\title{
3. Begriffe: bürokratischer Apparat, Interpellation, koloniales Subjekt
}

Alle Texte des Korpus dieses Buches - so die These - sind Teil, Ergebnis und Instrument des »bürokratischen Apparats«, jener Textproduktions- und »Datenverarbeitungsmaschinerie« (Reckwitz 2012: 113), die in den ersten Jahrzehnten der europäischen Expansion unter der beginnenden spanischen Kolonialherrschaft etabliert wurde. Auf die immense Bürokratie, die der Zentralmacht die Kontrolle über die überseeischen Provinzen des spanischen Kolonialreiches gewährleisten sollte, haben verschiedene Autoren unter verschiedenen Bezeichnungen aufmerksam gemacht: Folger (vgl. 2011) und BeasleyMurray (vgl. 2010) nennen sie »bureaucratic apparatus«; Brendecke spricht von verstärktem »Mediengebrauch « (2009b: 7) bzw. von der Koppelung »herrschaftlicher Beobachtung « und der »politischen Kommunikation«, der Verbindung des »kommunikativen und des epistemischen Settings« (2009a: 42); nach Lienhard (2003: 51) steht die »administrative, diplomatischer oder rechtliche Schrift« seit der Errichtung des »bürokratischen Apparats« stellvertretend für die imperiale Macht (vgl. auch ebd.: 63); »ciudad letrada« heißt sie bei Rama (1998). Die vorliegende Studie arbeitet mit dem Begriff »bürokratischer Apparat«. Doch was ist genau darunter zu verstehen? Welche Funktionen erfüllt er? Diese Frage soll in den nächsten Abschnitten geklärt werden, um später bei den Analysen der Texte unseres Korpus auf die einzelnen Punkte zurückgreifen zu können.

Zunächst schuf der bürokratische Apparat die Vorbedingungen des Regierens und Herrschens: Die Gesetze, Erlasse und Befehle der Zentrale mussten in die tausende von Meilen entfernten Gebiete des expandierenden Imperiums transportiert - übermittelt - werden. Ángel Rama spricht in seinem Werk La ciudad letrada von einer »Art Schriftnabelschnur« (ebd.: 46), welche die überseeischen Provinzen mit Befehlen und Schreibmodellen versorgt habe. Die Schiffe seien permanente Überbringer von schriftlichen Botschaften 
gewesen, die den Kolonisten immer neue Anweisungen gegeben hätten; [D]el mismo modo éstos procedían a contestar, a reclamar, a argumentar, haciendo de la carta el género literario más encumbrado, junto con las relaciones y crónicas ${ }^{1}$ (ebd.: 47). Das »komplexe Kommunikationsnetz«, das den Kontinent in der Folge überziehe, zeichne sich durch hohe Redundanz aus:

[L]as cartas se copian tres, cuatro, diez veces, para tentar diversas vías que aseguren su arribo; son sin embargo interceptadas, comentadas, contradichas, acompañadas de nuevas cartas y nuevos documentos. Todo el sistema es regido desde el polo externo (Madrid o Lisboa) donde son reunidas las plurales fuentes informativas, balanceados sus datos y resueltos en nuevas cartas y ordenanzas. Tal tarea exigió un séquito, muchas veces ambulante, de escribanos y escribientes, y, en los centros administrativos, una activa buracracia, tanto vale decir, una abundante red de letrados que giraban en el circuito de comunicaciones escritas, adaptándose a sus normas y divulgándolas con sus propias contribuciones. ${ }^{2}$ (Ebd.; Hervorhebung SG)

Ramas kolonial-kommunikatives Perpetuum mobile entspricht dem bürokratischen Apparat, von dem oben die Rede war. Allerdings suggeriert die Bezeichnung »Apparat« etwas Statisches, Etabliertes; für mein Verständnis des Begriffs ist jedoch der von Rama hervorgehobene Aspekt des Dynamischen, der Bewegung, Zirkulation und konstanten Neubildung, an der alle Kommunikationsteilnehmer mitwirken, zentral. Indem Schriftstücke produziert werden, werden die vorgegebenen Normen übernommen und gleichzeitig weitergegeben und verbreitet. Jeder letrado, der ein Schriftstück verfasst, setzt die übernommenen Normen in Umlauf und wird zum Mitglied des Apparats, zum »aktiven« (ebd.: 47) Bürokraten.

Als »Stunde Null« (»grado cero«) des Einfalls der Schrift nach westlichem Zuschnitt bezeichnet Lienhard (2003: 50) Kolumbus' Notiz vom 11. Oktober 1492, dem Tag der >Entdeckung der ersten karibischen Insel. Der Kapitän habe damals festgehalten, dass er den Anwesenden und seinem Schreiber Rodrigo d'Escobedo aufgetragen habe, seine Inbesitznahme des Landes zu beglaubigen und zu bezeugen (vgl. ebd.: 46). Diese und weitere >Eroberungen stützen sich anfangs - so Lienhard - nicht auf politisch-militärische Überlegenheit, sondern auf »el prestigio y la eficacia casi mágica que [los actores; SG] atribuyen a la escritura $\aleph^{3}$ (ebd.: 47). Bei der Landnahme hätten sie sich auf ein Papier berufen, die »capitulación« (ebd.: 46), in der ihn die katholischen Könige dazu autorisiert hätten. War dieses Procedere anfangs nichts weiter als ein »[B]luff" (ebd.: 49; Hervorhebung i.O.) - so Lienhards treffende 
Bezeichnung -, habe der nur wenige Jahrzehnte später installierte »aparato burocrático« dem Herrscher als Instrument dazu gedient, das in den Schriften Bestimmte und Festgelegte umzusetzen. »Los autóctonos, despojados >legalmente (por la escritura) de sus tierras, sometidos a juicios por su >idolatría<, no pudieron ignorar por mucho tiempo el aparente poder - un poder delegado - de la escritura administrativa, diplomática o judicial.« (Ebd.: 51) Der bürokratische Apparat diente also als Instrument der Durchsetzung der Macht.

Neben der Funktion des Regierens und der Durchsetzung und Sicherung der Macht hat der bürokratische Apparat eine Kontrollfunktion inne, verkörpert durch die Schreiber (escribanos). Als Beobachter und Gedächtnis des Königs (»Ojo y memoria del rey«, ebd.: 49) wahrte er die Kontrolle des Souveräns in jedem Moment des »europäischen Vordringens« (ebd.), in jedem Konflikt zwischen Erobern und Eroberten, aber auch zwischen den Eroberern.

Um ein Instrumentarium zur Analyse von Texten zu entwickeln, gehe ich noch einmal zurück auf Folger, der den bürokratischen Apparat (»bureaucratic apparatus«) als "a result and instrument of colonial expansion« (2011: 13) versteht. Die Funktion dieses Apparats bestehe darin, dass er »Standardsubjekte« (»Standard s subjects«) produziere, »who were compliant with the ideology of colonial rule« (ebd.). Indem die vom bürokratischen Apparat hervorgebrachten Subjekte mit der kolonialen Ideologie konform sind, werden also koloniale (textuelle) Subjekte hervorgebracht. Um diesen Mechanismus zu erklären, greift Folger auf den althusserschen Begriff der »Interpellation« zurück. Diesen setzt er als Werkzeug ein »to analyze the interplay between institutionalized pracices and subject constitution « (ebd.: 40). Das Subjekt entsteht also gemäß dieser Theorie im Wechselspiel mit institutionellen Praktiken, etabliert durch und über den bürokratischen Apparat. Wie Reckwitz zum gleichen Begriff der Interpellation ausführt, entstehe das Subjekt

immer in einer Konstellation kultureller Interpellation, der>Anrufung<innerhalb einer diskursiven Ordnung [...]. Der Polizist - so Althussers vielzitiertes Beispiel - ruft den Passanten mit >He, Sie da! sich um - es sieht sich selber damit angerufen, es gliedert sich selber in die diskursive Ordnung ein. (Reckwitz 2012: 92)

Der bürokratische Apparat lässt über die Praktiken der Institutionen - wie wir gesehen haben, handelt es sich im Falle des expandierenden spanischen Imperiums um Praktiken vornehmlich der Schrift - die Einzelnen zur Feder greifen und so zum kolonialen Subjekt werden: kolonialisiertes Subjekt, indem 
es sich dem System und seinen Normen unterwirft und sie sich zu eigen macht; kolonialisierendes Subjekt, indem es als Beamter oder Kollaborateur der Bürokratie das Archiv des Imperiums nährt (vgl. Folger 2011: 6, 50). Auf diese Weise gelingt es, die Untertanen in die koloniale Unternehmung fest einzubinden und ihre automatische Reproduktion über die Generierung von Texten zu sichern.

Angesichts einer gewissen Unschärfe, die dem Begriff »koloniales Subjekt« innewohnt, könnte man sich zwar die Frage stellen, ob sich damit die koloniale Situation angemessen erfassen lässt. Doch gerade eine gewisse Offenheit bringt den Vorteil mit sich, dass er die Situation als Ganzes in den Blick nimmt und damit außerhalb einer allzu simplen Täter/Opfer-Logik operiert. Dies schafft die Voraussetzung dafür, an jede einzelne zu analysierende koloniale Situation neu heranzutreten, ohne dass mit den Begrifflichkeiten bereits Vorannahmen getroffen würden, die unter Umständen auf die konkrete Situation nicht zutreffen. Einschränkend muss allerdings gesagt werden, dass der Begriff »koloniales Subjekt« spätestens im Kapitel zu den Prozessakten, aber auch in demjenigen zum »Jnsel«-Text, gewinnbringend durch den Begriff »Subjektgefüge« ersetzt werden kann. Die Mechanismen, die in beiden Begriffen angesprochen werden, sind die Gleichen. Der Unterschied lässt sich auf einer anderen Ebene ausmachen: Kommen die Stimmen in den Briefen letztlich aus einem Munde beziehungsweise aus einer Feder - auch wenn Mechanismen wirken, die nicht der Quelle selbst entstammen -, lässt sich eine solche Zuordnung in den Akten und dem »Jnsel«-Text kaum vornehmen.

Die Begriffe bürokratischer Apparat, Interpellation, koloniales Subjekt und Subjektgefüge werden stets im definierten Sinne verwendet. Analog dazu werden die Begriffe kolonialer Text und koloniale Situation im Sinne Kienings (vgl. 2003: 189) verstanden; ein kolonialer Text ging aus einer kolonialen Situation hervor und macht Letztere als solche kenntlich. Wichtigstes Merkmal des kolonialen Textes ist, dass er Argumente für die >Überlegenheit der Europäer liefert und - so möchte man hinzufügen - die Überlegenheit produziert und festschreibt. Wie dies genau geschieht und wie die koloniale Situation jeweils genau aussieht, sollen die folgenden Textanalysen des Korpus aufzeigen. 